\title{
Event-related potentials in cognitive neuropsychology: Methodological considerations and an example from studies of aphasia
}

\author{
TAMARA Y. SWAAB \\ University of Califormia, Davis, California
}

\begin{abstract}
Recording event-related potentials (ERPs) from neurological patients introduces some methodological problems that are unique to this type of work. Important issues include, for example, the signalto-noise ratio in patients relative to control subjects and changes in conductivity that are due to brain lesion. Therefore, in order to be able to reliably interpret possible changes in the ERP effects of braindamaged patients as reflecting changes in underlying cognitive processes, it is important to clearly identify the factors that might contaminate the results of the experiments and to apply appropriate controls. Possible controls are discussed, and, as an example, some studies illustrating the use of ERPs in aphasic patients are reviewed.
\end{abstract}

Event-related potentials (ERPs) are now a wellestablished means of studying human brain function. The power of this method lies in its flexibility and its utility for assessing everything from sensory to motor functions. Perhaps, however, it has been its ability to index various aspects of cognitive function that has most tantalized experimentalists and clinicians. The focus of this paper is on methodological issues involved in the utilization of ERPs for the study of the functional nature of cognitive deficits in brain-damaged patients. After a brief, selective overview of the use of ERPs in neurological and psychiatric patients, studies that have used the ERP method to investigate the nature of the deficits that underlie problems in spoken language comprehension in aphasic patients will be reviewed. These studies of ERPs in aphasia will serve to illustrate the methodological issues that arise in cognitive neuropsychological studies that use ERPs.

\section{Clinical Studies}

Traditionally, ERPs have been used clinically either as a way to localize the source of a particular sensory deficit or as a diagnostic tool in certain patient populations. The

The aphasia work reported in this paper was supported by Grant 560 264-040 from the Dutch Organization for Scientific Research (NWO) and was performed with Colin Brown and Peter Hagoort at the Max Planck Institute for Psycholinguistics in Nijmegen. I thank them for their scientific contribution to all the parts of this work. I am grateful to Mick Rugg, Colin Brown, and Peter Hagoort for organizing the workshop entitled "ERPs and Neuropsychology: Problems and Potentials" in San Diego, where many of the methodological issues that are addressed in this paper were discussed. The writing of this paper was supported by Grant NS 17778 to R. T. Knight, McDonnell-Pew Foundation Grant 9446 to M. S. Gazzaniga, and McDonnell-Pew Foundation Grant 97-11 to T.Y.S. I thank Martin Eimer, Ron Mangun, and two anonymous reviewers for their helpful comments on a previous version of this paper. Correspondence concerning this paper should be addressed to T. Y. Swaab, Center for Neuroscience, University of California, 1544 Newton Ct., Davis, CA 95616 (e-mail: swaab@marzen. ucdavis.edu). absence or delay of early sensory potentials can help to determine the locus of lesions in particular parts of the nervous system. For example, auditory ERPs (see, e.g., Stockard, Stockard, \& Sharbrough, 1980) and somatosensory ERPs (see, e.g., Jones, 1982) can be used to localize damage to specific sites within the ascending sensory pathways (see Regan, 1989, for an overview). One of the most well-known clinical applications of ERPs is in audiometry, where, in addition to behavioral measures, the ERP has proved to be very reliable in determining whether there is hearing loss (see, e.g., Galambos, Hicks, \& Wilson, 1982), and this has been especially useful in populations unable to provide accurate or reliable responses in behavioral testing (see, e.g., Smith \& Picton, 1985). Similarly, visual ERPs have been successfully utilized in the diagnosis of disorders specifically affecting the visual system (see, e.g., Kuroiwa \& Celesia, 1981), as well as diseases such as multiple sclerosis that might affect vision (see, e.g., Halliday, 1982).

Relatively early in the history of ERP recording, however, researchers also evaluated the possibility of using changes in the amplitude and/or latency of cognitive ERPs to address a variety of clinical issues in neurological, psychiatric, and other clinical populations. At present, there is a very large literature on the clinical applications of ERPsfor example, in schizophrenics (see, e.g., Ford, Pfefferbaum, \& Roth, 1992; Pritchard, 1986), patients with Alzheimer's disease (AD; see, e.g., Polich, Ladish, \& Bloom, 1990), and learning-disabled children (see, e.g., Kraus et al., 1996). A comprehensive review of this literature is beyond the scope of the present paper; however, a brief comment on the relative success of ERP studies of different groups of patients helps illustrate both the difficulty and the promise of applying ERPs to clinical populations as a diagnostic or evaluative tool.

Much of the research on schizophrenic patients has concentrated on changes in the $\mathrm{P} 300$ component of the 
ERP - both in order to evaluate the diagnostic utility of $\mathrm{P} 300$ and in order to assess cognitive theories of schizophrenia (see, e.g., Ford et al., 1992; for a review, see Pritchard, 1986). P300 is a "cognitive ERP," because it is not elicited by the sensory aspects of the stimuli per se but instead is related to cognitive factors, such as attention and task relevance, and can even be elicited by the absence of a relevant stimulus (for a review on the P300 component, see Johnson, 1988). Most studies have employed some version of the classical oddball paradigm (see Donchin, 1979), in which the subjects have to detect infrequent targets in a series of frequently occurring nontargets. In normal, neurologically unimpaired subjects, P300 amplitude increases for low probability stimuli that are relevant and attended to by the subjects, and P300 latency increases as a function of the duration of stimulus evaluation time. Evidence from a large body of work has led researchers to propose that $\mathrm{P} 300$ is a sensitive indicator of deviance detection and, more specifically, that it reflects the process of updating one's internal neural model of the environment (context updating; see Donchin $\&$ Coles, 1988). Thus, given the fundamental aspects of mentation that are reflected by P300, it makes sense to use it in the evaluation of patients with cognitive disorders.

In general, in studies of schizophrenic patients, the amplitude of $\mathrm{P} 300$ has been found to be reduced relative to normal controls (although some evidence indicates that this is not the case for the visual modality; see Pfefferbaum, Ford, White, \& Roth, 1989). This reduction does not appear to be the result of medication or of the slowing of response time in these patients (see Pritchard, 1986). These results indicate that $P 300$ might be a sensitive marker for the diagnosis of schizophrenia. However, P300 is also reduced in other patient populations, such as AD patients (see, e.g., Polich et al., 1990). In addition, it is not clear whether changes in the $\mathrm{P} 300$ component can be reliably detected at the individual subject level. Taken together, these P300 studies in schizophrenia and AD show that the P300 component of the ERP might be a useful tool for discriminating groups of schizophrenic and $A D$ patients from normal, neurologically unimpaired subjects, but it is unclear whether this measure is sensitive enough to reliably diagnose patients individually. ${ }^{1}$

In other patient populations, the use of ERPs does, however, appear very promising as a diagnostic tool. Kraus and colleagues (Kraus et al., 1996) tested learningdisabled children who had a deficit in the discrimination of the rapid acoustic changes that occur in speech (e.g., $/ \mathrm{d} \alpha / \mathrm{vs}$. $/ \mathrm{g} \alpha /$ ). They used the mismatch negativity (MMN) to establish whether these problems occur at a level that is prior to the conscious perception of these stimuli. The MMN is sensitive to changes in a series of simple or complex stimuli. It is elicited by physically deviant stimuli and does not require attention or a response. They found that the MMN was absent in learning-disabled children who had a poor discrimination of the $/ \mathrm{d} \alpha /-\lg \alpha /$ stimulus contrast, which indicates that their discrimination prob- lems occurred at the level of the auditory system and not from a higher level processing deficit. Even in individual subjects, the MMN appeared to be a sensitive indicator of good versus poor discrimination of acoustic contrasts, which makes this ERP component a good candidate for the diagnosis of the locus of acoustic discrimination problems in learning-disabled children.

\section{ERPs and the Neural Architecture of Behavior}

ERPs have also been used in efforts to investigate the neural architecture underlying certain types of behavior. For example, Knight (1996) recently proposed that a distributed limbic-neocortical network is involved in the orienting to and memory storage of novel events. He based this proposal on evidence that was obtained by recording ERPs from patients with various discrete neurological lesions produced by stroke. Specifically, Knight (1996) found that patients with unilateral hippocampal lesions in either the left or the right hemisphere showed a selective deficit in the electrophysiological response to novel stimuli - that is, infrequent stimuli, each presented only once, embedded in a sequence of repetitive background stimuli-in auditory and somatosensory modalities. The novel stimuli (complex tones, wrist shocks) were clearly deviant from the target and nontarget stimuli in this experiment. In normal subjects, the novel stimuli elicited a P3a component with a frontal scalp distribution, whereas the hippocampally lesioned patients showed a dramatically reduced $\mathrm{P} 3 \mathrm{a}$ to the novel stimuli. In earlier work, Knight and colleagues had shown that the $\mathrm{P} 3 \mathrm{a}$ response is also reduced in patients with local damage to the dorsolateral prefrontal cortex and the posterior association cortex (Knight, 1987; Yamaguchi \& Knight, 1991). Thus, the evidence from the P3a in various patient groups allowed Knight (1996) to define a cortical system for the processing of novelty.

It should be emphasized that this lesion approach is only fruitful in helping to delineate the anatomic and physiological underpinnings of behavior in combination with the neuropsychological evaluation of the behavioral problems. Also, the patients that are to be tested should have very focal lesions, as defined by computerized tomography (CT) or magnetic resonance imaging (MRI; see, e.g., Knight, 1997). Under these circumstances, the findings from this lesion approach, in combination with findings from intracranial recordings in patients and from animal studies (see Swick, Kutas, \& Neville, 1994), can help to determine the neural sources of ERP components, so that inferences can be made about the functionalanatomical significance of ERPs. In recent years, the specification of the neural sources of ERP components has been further facilitated by studies of neurologically normal subjects that have combined ERPs with neuroimaging methods that have a high anatomical resolution, such as positron emission tomography (PET) and functional magnetic resonance imaging (fMRI; see, e.g., Heinze et al., 1994; Mangun, Hopfinger, \& Heinze, 1998). 


\section{ERPS IN COGNITIVE NEUROPSYCHOLOGY}

Distinct ERP components have been related to different cognitive processes in normal, neurologically unimpaired subjects, and this knowledge has been used to address the question of what the underlying functional nature of cognitive deficits in brain-damaged patients may be. The use of ERPs in the characterization of cognitive impairments in certain patient populations is a relatively recent development (see Hagoort \& Kutas, 1995). Nonetheless, ERPs have been fruitfully applied to the study of functional deficits in a variety of neurological patient populations. For example, ERPs have been used to study the preservation of implicit memory (see, e.g., Rugg, Pearl, Walker, Roberts, \& Holdstock, 1994) and the nature of semantic deficits in patients with dementia of the Alzheimer's type (DAT; see, e.g., Schwartz, Kutas, Butters, Paulsen, \& Salmon, 1996); to study movement preparation (see, e.g., Cunnington, Iansek, Bradshaw, \& Phillips, 1995; Praamstra, Meyer, Cools, Horstink, \& Stegeman, 1996) and auditory selective attention in patients with Parkinson's disease (Karayanidis, Andrews, Ward, \& Michie, 1995); to study perceptual processing in patients with closed head injury (Heinze, Münte, Gobiet, Niemann, \& Ruff, 1992); to study implicit recognition of familiar faces in prosopagnosia (Renault, Signoret, Debruille, Breton, \& Bolgert, 1989); to study the control of visual space (Proverbio, Zani, Gazzaniga, \& Mangun, 1994) and the organization of language in the left and right hemispheres of split-brain patients (see, e.g., Kutas, Hillyard, \& Gazzaniga, 1988); and to study the nature of the deficit that underlies spoken language comprehension problems in aphasia (see, e.g., Hagoort, Brown, \& Swaab, 1996; Swaab, Brown, \& Hagoort, 1997, in press). At the end of the present paper, our studies of language comprehension deficits in aphasia will be presented as examples that illustrate the utilization of ERPs in the investigation of functional deficits in braindamaged patients. But first, some methodological issues involved in testing brain-damaged patients in general and, more specifically, in testing brain-damaged patients with ERPs will be discussed.

\section{General Issues in Testing Patients}

There are certain issues involved in testing patients that are not specific to the ERP approach but need to be carefully considered whenever patients are being tested in scientific experiments. The first general issue has to do with the possible inferences that one can make about the normal functioning of the mind from the experimental results that are found in patients with brain damage. At least three types of difficulties can emerge in establishing the relation between mind and brain. First of all, the correlation between the type of deficit and the locus of the lesion is far from perfect. This can be illustrated with examples from aphasia research. Classically, lesions in Broca's area have been associated with problems in produc- ing speech but relatively spared comprehension, whereas lesions in Wernicke's area have been associated with severe comprehension deficits but relatively fluent (although incomprehensible) speech. However, several studies have shown that there is no perfect relation between the locus of the lesion and the type of aphasia syndrome. Patients with anterior lesions will sometimes exhibit severe comprehension problems, and, on the other hand, some patients with posterior lesions, including ones in Wernicke's area, do not always have comprehension deficits (see, e.g., Basso, Lecours, Moraschini, \& Vanier, 1985; Caplan, Baker, \& Dehaut, 1985; Poeck, De Bleser, \& von Keyserlingk, 1984). This raises the following question: What is the appropriate level at which to map the cognitive architecture onto the neural architecture? Should we think in terms of particular brain areas, in terms of distributed networks, or in terms of a combination of both?

Second, cognitive processes that are identified in our models may not always correspond to particular areas in the brain. Often it will be the case that one brain structure is subserving more than one cognitive function. On the other hand, one function might be subserved by more than one brain structure. Under certain circumstances, however, mind-brain relations can be reliably identified, even in patients with large lesions. Dronkers (1996) has demonstrated that patients with one particular symptom-namely, apraxia of speech-showed $100 \%$ overlap of lesion in the left precentral gyrus of the insula. In addition, she was able to show that this particular brain area was spared in patients with aphasia but without apraxia of speech. Apparently, certain well-defined functions are localizable to specific areas of the brain. On the other hand, it is not likely that more complex cognitive functions will be subserved by one particular area of the brain, and, hence, a direct mapping of the mind and brain might not always be as clear as the one shown in the Dronkers (1996) study.

The third problem in identifying the relation between the neural and cognitive architecture is that we have to assume transparency (Caramazza, 1992): The cognitive system of the brain-damaged patient should be exactly the same as that of a neurologically unimpaired person, except for one local functional modification. It is not clear whether the brain lesions produced by stroke, tumor, and injury will always obey this strict rule.

The second general issue concerns the single-case versus group study controversy. Caramazza and colleagues have argued that the only way to draw valid inferences about the unimpaired cognitive system from the impaired cognitive functions in patients with brain damage is to use single-case methodology (see, e.g., Caramazza, 1986; Caramazza \& Badecker, 1989; Caramazza \& McCloskey, 1988; McCloskey \& Caramazza, 1988). This argument is grounded in the idea that brain damage is an "experiment of nature" and that grouping brain-damaged patients will most likely violate the assumption of homogeneity. That is, it is impossible to know whether two patients have brain 
damage that causes identical functional damage, and this can only be established on the basis of extensive experimentation with these two individuals.

Several authors have taken issue against this strict single-case approach (see, e.g., Bates, Appelbaum, \& Allard, 1991; Bub \& Bub, 1988; Caplan, 1988; Hagoort, 1990; Robertson, Knight, Rafal, \& Shimamura, 1993; Whitaker \& Slotnick, 1988; Zurif, Swinney, \& Fodor, 1991). The defenders of group studies of patients with brain damage point out that homogeneity is often violated in the normal population as well, where single individuals who show a pattern of results that deviates from the majority are treated as noise. In this sense, normal experimental psychology does not differ as radically from neuropsychology as Caramazza and colleagues argue. In addition, the single-case approach is sometimes less well suited for addressing certain valuable questions in experimental psychology. For example, in psycholinguistics, important questions about the temporal orchestration of real-time language processes are often best studied in experiments with groups of subjects that can be evaluated statistically, so that the variation in performance that might obscure specific small but theoretically important effects can be reduced. This last argument also highlights a property of statistics that is relevant with respect to the issue of homogeneity. Large variability in performance, such as might be expected in patients that have a variety of functional lesions, will not lead to statistically significant results. Statistically significant results in patient groups, therefore, indicate small variability in the particular behavior that is being tested in the experiment, which allows one to make meaningful inferences about (changes in) this behavior in patients.

The issue of single-case versus group studies is relevant when we consider the use of ERPs in brain-damaged patients. Under certain circumstances, it might be possible to obtain ERP data from single subjects-for example, by running the same experiment several times with the same subject or by using single trial statistics. In general, however, the small size of the ERP effects will require an averaging procedure that includes several subjects in order to obtain reliable results, and, therefore, a strict singlecase approach might not be feasible. However, singlesubject data can (and should) be reported. This-together with the patients' profile on the relevant neuropsychological tests and CT- or MRI-defined lesion information-will allow the evaluation of potentially interesting individual differences.

\section{Issues in Using ERPs in Brain-Damaged Patients and Possible Control Procedures}

In order to be able to reliably interpret possible changes in the ERP effects in neurological patients as reflecting deficits in certain cognitive processes, it is important to identify the factors that might possibly contaminate the results of the experiments and to apply the appropriate controls (see also Hagoort \& Kutas, 1995). One of the possible confounding variables in testing patients with ERPs is that the signal-to-noise ratio can be worse in braindamaged patients than in the control subjects. In the patients, more trials could be contaminated by artifactsfor instance, because the patients have difficulties in refraining from blinking. To be able to reliably interpret, for example, a reduction in a particular ERP component in patients relative to their control subjects, it is important to have comparable signal-to-noise ratios in these groups. One way to make the signal-to-noise ratio in the patient group more comparable to that in the control subjects is to randomly delete trials in the control group in order to arrive at the same total number of trials per averaged waveform. Especially in language experiments, however, because of the limited number of trials per condition, this might not be a viable option. ${ }^{2}$ In that case, the other possibility is to improve the signal-to-noise ratio in the patients by using an eye correction procedure rather than by rejecting trials (see, e.g., Brunia, Möcks, \& Van Den Berg-Lenssen, 1989; Gratton, 1998; Gratton, Coles, \& Donchin, 1983). In most eye correction procedures, the trials that are contaminated by eyeblinks, eye movements, or both are corrected, so that these trials can be retained. This has the additional advantage of reducing the task demand on the patients. Not allowing subjects to blink at certain periods of time during the experiments resembles a dual-task situation (see, e.g., Verleger, 1991), and even normal, neurologically unimpaired subjects sometimes have a hard time maintaining the appropriate blink regime. One can imagine that this dual-task situation is even harder for patients with brain damage. In addition, some patients with severe comprehension deficits will simply be unable to understand when they are allowed to blink and when not, and, in this case, the use of an eye correction procedure is unavoidable.

Another factor that can confound the comparison of the ERP data of brain-damaged patients with those of their controls is the physical differences caused by skull defects and brain atrophy in the patients. Atrophy might lead to changes in conductivity that actually lead to an increase in the size of ERPs. This factor can complicate the use of source localization techniques (e.g., BESA), because they make strong assumptions about conductivity. Also, sulcal widening might change the geometry of sources, which could lead to apparent changes in the topography of ERP components. In addition, given that it is not easy to quantify the consequences of brain lesions on volume conduction, one has to be very careful in assigning a cognitive-functional interpretation to subtle differences in scalp distributions of the ERP effects between different subject groups. At the very least, if one wants to make between-group comparisons of the topographical distribution of the effects, a rescaling procedure should be applied to the data (see, e.g., McCarthy $\&$ Wood, 1985). Also, in order to evaluate whether topographic changes are specific to particular cognitive processes or are a more general, nonspecific effect of brain damage on the topographic distribution of ERP components, it is imperative to compare multiple components 
in this respect (see, e.g., Friedman, Simpson, \& Hamberger, 1993). Topographic changes in one ERP component but not in others will help determine the specificity of these changes.

A very important issue in neuropsychology in general and in testing patients with ERPs in particular is the selection of patients and the choice of control subjects. In the selection of the patients, a good etiology is necessary. In group studies, it is crucial that the selected patients are matched on as many variables as possible. Some of the crucial variables are: the cause of brain damage-for example, a cerebral vascular accident (CVA), cerebral meningitis, $\mathrm{AD}$, a closed head injury, developmental disorders-exact specification of the neuropsychological problems, and the locus of the lesion identified by an experienced neurologist or radiologist from CT or MRI scans. In the best of all worlds, the patients that one selects for a study should have the same cause of the brain damage (e.g., CVA), show deficits in a particular cognitive function (e.g., deficits in understanding complex grammatical structure), and have a focal lesion (e.g., in the inferior frontal lobe of the left hemisphere). Depending on the nature of the study, other variables might be important in the selection of the patients. For example, in language studies, patients should be premorbidly right-handed so that they are left hemisphere dominant for language. ${ }^{3}$

The control subjects have to be selected carefully as well. If the patient group of interest is aged, then the results from the patients have to be compared with those from a group of normal age-matched controls in order to control for the nonspecific effects of aging on ERP components. Age-related changes in the amplitude, latency, and topography of ERP components have been reported in several studies (see, e.g., Friedman et al., 1993; Iragui, Kutas, Mitchener, \& Hillyard, 1993; King \& Kutas, 1995a; Knight, 1987; Polich, 1996). But one should consider other variables in addition to age. For example, patients who have undergone temporal lobectomy for the treatment of epilepsy are often still on anticonvulsive drugs, which means that controls should be used that are on the same medication (Rugg, Roberts, Potter, Pickles, \& Nagy, 1991). ${ }^{4}$

It is difficult to predict what the effect of brain damage itself will be on cognitive ERP components, and it is crucial to control for possible nonspecific effects of brain damage on the ERPs. One way to do this is by comparing the results from the experimental patients with those from a group of brain-damaged patients who do not have the cognitive deficit that the experimental subjects show. For example, when testing aphasic patients with a lesion in the left hemisphere, a control group of nonaphasic patients with a lesion in the right hemisphere can be tested as well. A comparison of the ERP pattern of results for the aphasic and the nonaphasic patients will reveal to what extent changes in language-sensitive ERP components in the aphasics are due to their underlying deficit, rather than being a more general effect of brain damage on cognitive ERP components.
Another way to control for the nonspecific effects of brain damage on cognitive ERP components is to use a within-subjects experimental design, in which the same cognitive ERP component can be compared within subjects over different experimental conditions. In this way, the pattern of results for the patient group can be compared with the pattern of results for the normal controls, without the necessity of doing between-groups comparisons of ERP amplitude and latency.

A further important control is the comparison of the experimental ERP component to ERP components that should not be changed by the deficit in the patient group of interest. For example, in a test of patients with aphasia, changes might be expected in the N400 component that is sensitive to the semantic aspects of the input (see, e.g., Kutas \& Hillyard, 1980), and/or in ERP components that are sensitive to syntactic processing - as, for example, the syntactic positive shift (SPS; Hagoort, Brown, \& Groothusen, 1993) or P600 (Osterhout \& Holcomb, 1992) and the left anterior negativity (LAN; see, e.g., Friederici, Pfeifer, \& Hahne, 1993; King \& Kutas, 1995b; Kluender \& Kutas, 1993; Münte, Heinze, \& Mangun, 1993; Neville, Nicol, Barss, Forster, \& Garret, 1991). In principle, however, these patients should show a relatively. normal P300 in a classical oddball paradigm, where subjects have to detect infrequent low tones in a series of high and low tones (see, e.g., Donchin, 1981). Overall, the comparison of the experimental cognitive ERP component with one or more of the control components will help to determine the extent to which possible changes in the experimental component can be dissociated from the effect of brain damage on cognitive ERP components in general.

Finally, one last practical issue might play a role when testing patients with brain damage. For a variety of reasons, these patients often cannot be tested for very long periods of time. It is important to allow for little breaks throughout the whole experiment. These breaks can also be used to repeat the instructions and to motivate the subjects again to focus on the experiment. In general, to be able to obtain ERP data that are relatively free of artifacts, the total ERP session, including the application of the electrodes, should probably not exceed two hours. This, of course, depends on the patient group-healthy college-aged dyslexics, for example, would not have this limitation (see, e.g., Johannes, Mangun, Kussmaul, \& Münte, 1995).

In general, possible reductions in the signal-to-noise ratio and changes in conductivity in patients, in comparison with their controls, are variables that might contaminate the comparison of their ERP results. However, these issues can be addressed by having an equal number of trials in the patients and their controls and by being cautious in interpreting topographical differences between subject groups. In addition, it is important to carefully select patient groups, so that they are matched on certain crucial variables, to test the appropriate control groups, and to test patients on more than one ERP component. In practice, it might not always be possible to apply all of 
these control measures. But, in the interpretation of changes in cognitive ERP components in brain-damaged patients relative to their controls, it is essential to keep these issues in mind.

Given all of these methodological concerns, what made it worthwhile to use ERPs in the study of the functional nature of cognitive deficits in brain-damaged patients? This was motivated by some unique characteristics of ERPs. ERPs are a real-time measure of cognitive processes as they are being executed, and they provide a continuous measure of the neural activity underlying cognitive processes. In principle, then, the use of ERPs introduces the potential for very detailed analyses of possible changes in the time course of cognitive processes in various patient populations. In addition, continuous measurement allows for the analysis of more than the discrete behavior related to a particular stimulus. For example, ERPs can be generated by the cognitive processes that prepare a response, as well as by the response itself.

Another interesting property of ERPs is that they can be recorded without imposing additional, potentially interfering task demands on the patients. This opens the possibility of testing a variety of patient populations that are hard to test in behavioral experiments. Wernicke's aphasics, for example, often have severe comprehension deficits, which can make it very difficult to test them in behavioral experiments. In patients with DAT, the requirement of making a two-choice yes or no response will greatly impair their performance (Ober \& Shenaut, 1995); the absence of additional task requirements while measuring ERPs precludes task-interference effects on the cognitive processing operations in these patients. Another example is the performance of Parkinson's patients on behavioral tasks: If a Parkinson's patient shows impaired performance on some kind of behavioral task-let's say a buttonpress - is this due to an underlying cognitive impairment or to the fact that this patient is severely impaired in his or her movements? The continuous nature of the ERP signal provides us with a means of looking at the cognitive processes that prepare the response and those that follow the response, which, in principal, can help tease apart the relative contributions of impaired cognitive processes and impaired motor behavior in groups such as Parkinson's patients. In order to illustrate in more detail how ERPs can contribute to our understanding of the nature of cognitive deficits in brain-damaged patients, an example from studies of aphasia follows.

\section{ERPS IN THE STUDY OF THE FUNCTIONAL LOCUS OF COMPREHENSION DEFICITS IN APHASIC PATIENTS 5}

The ability to understand spoken words and sentences can be severely disrupted in aphasia, as is evident from clinical assessment as well as from experimental results. A central issue in aphasia research is whether these comprehension deficits in aphasic patients are due to losses of stored linguistic information or, alternatively, to a dis- ruption of the processes that access and/or exploit this information in real time. Depending on the kinds of tasks that were used to test comprehension deficits, studies have found evidence supporting both loss of information and processing deficits. Studies that used tasks such as sentence-picture matching, object naming, and sentence completion support the idea that some linguistic representations are missing, distorted, or no longer accessible in aphasia (see, e.g., Berndt \& Caramazza, 1980; Goodglass \& Baker, 1976; Grober, Perecman, Kellar, \& Brown, 1980; Zurif, Caramazza, Myerson, \& Galvin, 1974). These tasks are referred to as "off-line" tasks because they require subjects to operate on the end product of the language comprehension process. That is, in an off-line task, subjects can give their responses after the relevant language processes have been completed, which permits strategies unrelated to language processing to be involved in producing the response. Although important, this type of research does not provide direct information on distortions of the real-time processes that act on the stored linguistic information (Hagoort \& Kutas, 1995). Investigating real-time processes that occur during language understanding requires "on-line" methods, which tap into the language comprehension processes as they unfold in real time.

Since the early eighties, aphasia research has begun to use on-line tasks, such as lexical decision. In these studies, the patients were required to make fast and accurate responses to linguistic stimuli but were kept unaware of the linguistic process that was being manipulated. For example, in a lexical decision task, subjects are asked to decide as quickly and as accurately as possible whether a letter string or a sound sequence is a word or not. However, the real, underlying question in many lexical decision studies is about the processing benefits for words that are preceded by related words or sentences versus the costs for words that are preceded by unrelated words or sentences. In general, these types of tasks can reveal which real-time processing characteristics of the comprehension process are impaired, which helps to elucidate the functional nature of comprehension deficits in aphasia. The conclusion from on-line studies in aphasia has been that aphasic comprehension deficits are not entirely due to a loss of stored linguistic representations but rather to the inability to access and/or exploit these representations in real time (see, e.g., Baum, 1989; Blumstein, Milberg, \& Shrier, 1982; Friederici, 1983, 1985; Friederici \& Kilborn, 1989; Friederici, Wessels, Emmorey, \& Bellugi, 1992; Haarmann \& Kolk, 1991, 1994; Hagoort, 1990, 1993, 1997; Milberg, Blumstein, \& Dworetzky, 1987; Milberg, Blumstein, Katz, Gershberg, \& Brown, 1995; Ostrin \& Tyler, 1993; Swinney, Zurif, \& Nicol, 1989; Tyler, 1985; Tyler, Ostrin, Cooke, \& Moss, 1995). For example, Milberg and colleagues (Milberg \& Blumstein, 1981; Milberg et al., 1987) have found that Wernicke's aphasics, who were severely impaired in an explicit semantic judgment task, consistently showed semantic facilitation effects in a priming experiment- that 
is, faster lexical decisions to target words that are related to a previous prime word than to target words that are unrelated to a previous prime word. Apparently, the lexical-semantic impairments of Wernicke's aphasics are most evident when they are asked to consciously elaborate on aspects of activated word meanings (Graf \& Mandler, 1984; Hagoort, 1993). When lexical-semantic processing is assessed more implicitly, as in the priming studies with a lexical decision task, these patients do not show an impairment.

These results have led to the idea that real-time processing impairments must be considered an important factor in the explanation of language comprehension deficits in aphasia. However, it is still a matter of debate as to what the exact nature of these processing deficits in aphasic comprehenders may be. Several authors have entertained the possibility that Broca's aphasics in particular have an impairment in automatically accessing the representations in the mental lexicon (see, e.g., Baum, 1989; Milberg et al., 1987; Milberg et al., 1995; Swinney et al., 1989). But other evidence suggests that the integration of lexical information into a higher order message representation might also be impaired in aphasia (see, e.g., Hagoort, 1990, 1993, 1997; Hagoort et al., 1996; Swaab et al., 1997, in press; Tyler \& Ostrin, 1994; Tyler et al., 1995). The latter idea was tested in a series of three studies in which ERPs were used to investigate the functional locus of comprehension deficits in aphasia (Hagoort et al., 1996; Swaab et al., 1997, in press).

\section{The N400}

The most relevant ERP component for the studies that will be discussed below is the N400. The N400 is a negative peak in the ERP waveform that is maximal over the centroposterior regions of the scalp (Kutas \& Hillyard, 1983 ). In young subjects, the $N 400$ reaches its maximum amplitude between 380 and $440 \mathrm{msec}$ after stimulus onset. However, this may be delayed in elderly subjects (see, e.g., Gunter, Jackson, \& Mulder, 1992). Within the domain of language processing, the $\mathrm{N} 400$ is observed with written input, with words or sentences that are presented in the auditory modality, with naturally produced connected speech (see, e.g., Holcomb \& Neville, 1991), and with sign language (Kutas, Neville, \& Holcomb, 1987).

The N400 is especially sensitive to semantic aspects of the linguistic input. This was first reported by Kutas and Hillyard (1980), who found that the amplitude of the N400 to visually presented sentence-final anomalous words ("He spread the warm bread with socks") was increased in comparison with the $\mathrm{N} 400$ to sentence-final congruent words ("It was his first day at work"). This difference in the amplitude of the $\mathrm{N} 400$ is referred to as the $N 400$ effect. In contrast to semantic anomalies, physically deviant words (e.g., words printed in a larger font size) elicited a positive potential rather than a negativity. Other nonsemantic deviations, such as musical or gram- matical violations, also failed to elicit the $\mathrm{N} 400 \mathrm{effect}$ (see, e.g., Besson \& Macar, 1987; Friederici, 1995; Hagoort et al., 1993; Kutas \& Hillyard, 1983; Münte et al., 1993; Osterhout \& Holcomb, 1992).

Important for the conclusions of our experiments in aphasic patients (Hagoort et al. 1996; Swaab et al., 1997, in press) is the question of what the N400 effect reflects about the underlying comprehension processes. A number of studies support the idea that, in the context of a word or a sentence, the N400 effect is reflecting lexical integration and not lexical access. The results of recent lexical priming studies have shown that, in the context of another word, the $\mathrm{N} 400$ effect is not modulated by the spreading of activation in a semantic network or by automatic access to lexical representations, but primarily reflects postlexical processes that are involved in lexical integration (Brown \& Hagoort, 1993; Chwilla, 1996; Chwilla, Brown, \& Hagoort, 1995; Holcomb, 1993; Rugg, Furda, \& Lorist, 1988). Brown and Hagoort (1993) found a priming effect for reaction times in a lexical decision task when the presentation of the visual prime was masked, but, under the same circumstances, no N400 effect was obtained. In another priming study, Holcomb (1993) showed that the stimulus degradation of visually presented target words did not modulate the size of the $\mathrm{N} 400$ effect, whereas the reaction times showed larger priming effects to the degraded than to the normal targets. These results indicate that the $\mathrm{N} 400$ priming effect is not sensitive to the automatic spreading of activation and the automatic lexical access process. In support of the idea that the $\mathrm{N} 400$ effect is sensitive to lexical integration processes, Chwilla (1996) found evidence that suggests that, in the absence of an overt task such as lexical decision, N400 priming effects are largely due to semantic matching, which is not unlike the integration process that occurs in the more common processing of sentences or discourse (Brown \& Hagoort, 1993; Neely, 1991). In both cases, word meaning has to be matched against the semantic specifications of the context. In sentence contexts, the finding of Van Petten and Kutas (1991) that the N400 to open class words is larger at the beginning of the sentence than at the end of the sentence is also consistent with the idea that the $\mathrm{N} 400$ effect is modulated by the lexical integration process. In light of these findings, the changes in the amplitude and/or latency of the N400 effects in aphasic patients, relative to their controls, are interpreted to reflect a deficit in lexical integration.

\section{Methodological Considerations}

Before the results of the studies in which we used ERPs to investigate language comprehension deficits in aphasia are presented, the methodological controls that were implemented in these studies will be discussed, with reference to the issues that were addressed earlier in this paper.

In all three studies, a number of control measures were taken. First, a group of neurologically unimpaired con- 
trol subjects who were matched with respect to age and level of education with our aphasic patients was tested. This was done in order to control for the nonspecific effects of aging on ERPs.

Second, in two of the studies, we also tested a group of nonaphasic patients with lesions in the right hemisphere ( $\mathrm{RH}$ controls). It was established that this group was nonaphasic on the basis of their results on the Dutch version of the Aachen aphasia test battery (AAT; Graetz, De Bleser, \& Willmes, 1992). This RH group provided us with a control for the nonspecific effects of brain damage on ERP components. The N400 effects for the RH controls were in most cases relatively normal, which showed that brain lesions do not necessarily lead to major changes in the size and/or latency of all endogenous ERP effects. In general, the comparison of the results from the aphasic patients with those from these two control groups indicated that the changes of the N400 effects for the aphasic patients, relative to their controls, were most likely not a nonspecific effect of their brain lesion but were specific to the nature of their language impairment.

As a third control, we tested all the subject groups in the nonlinguistic classical oddball paradigm, where the subjects were asked to count infrequent low tones in a series of high and low tones. In all of the studies, a clear dissociation was found between the P300 effects of this nonlinguistic control experiment and the N400 effects of the aphasic patients. That is, the patients that showed a reduced N400 effect did not show a reduced P300 effect and vice versa. With the results of these control studies in mind, the changes in the N400 effects of the aphasic patients can be interpreted in terms of their language deficit.

A number of other issues were taken into consideration in the preparation of the experiments and in the analyses of the data. First, our patients were selected according to stringent criteria. The patients were all premorbidly righthanded, so that the left hemisphere was their languagedominant hemisphere. Furthermore, all but one of the subjects had the same etiology-namely, CVA. The patients were tested at least 6 months after the onset of their symptoms. All of the aphasic patients were diagnosed as Broca's or Wernicke's aphasics with the AAT. Moreover, since we were interested in language comprehension deficits, we made sure that all of the selected patients had light, moderate, or severe comprehension deficits on the comprehension subtest of the AAT. Second, we prepared as many linguistically controlled language stimuli as possible in each of the studies described below (at least 50 stimuli per condition), in order to achieve a minimum of 30 trials per individual after artifact rejection. In addition, in two of the three studies, we used the eye correction procedure that is described by Gratton et al. (1983), in order to increase our signal-to-noise ratio in those studies. After artifact rejection, the percentage of rejected trials was, on average, around $20 \%$ for the aphasic patients, around $23 \%$ for the RH control patients, and around $17 \%$ for the normal controls.

In the analyses of the data, we not only looked at the group-averaged ERP results but also performed a care- ful evaluation of the single-subject data. This evaluation of the individual subject data revealed that, despite considerable variation in the size of the effects, the ERP pattern of results that was found in the grand averages was also discernable in most of the individual subjects. The data from individual subjects, therefore, supported the conclusions that had been drawn from the group data.

\section{The Experiments}

The aim of the first experiment was to determine further the nature of lexical-semantic processing impairments in Broca's and Wernicke's aphasics (Hagoort et al., 1996). This was done by presenting these patients with spoken words in a two-word priming paradigm. The second word of a pair was either purely semantically but not associatively related (from the same semantic category: church-villa), associatively related (black-white), or unrelated to the first word in a pair (book-floor). The normal control subjects showed the expected N400 effect of priming: a reduction of the $\mathrm{N} 400$ amplitude to the semantically and associatively related words relative to the unrelated words (see Figure 1). The Broca's and Wernicke's aphasics also showed an N400 effect of priming, but the overall size of the $\mathrm{N} 400$ effect (the difference between the related and the unrelated condition) was reduced in the Wernicke's aphasics (see Figure 1).

Interestingly, however, when the data of the aphasic patients were analyzed according to the severity of their comprehension deficit, irrespective of their syndrome classification, the aphasic patients with more severe comprehension deficits (low comprehenders) showed a clear reduction of the $\mathrm{N} 400$ effect relative to a group of normal controls. In contrast, the patients that had only minor comprehension deficits (high comprehenders) showed N400 effects whose size was similar to that for the controls (not shown in figures).

The following conclusions were drawn from these results: First, the fact that similar results were found for the associatively related and for the purely semantically related words supports the idea that these patients are able to access information at the level of lexical semantics (Fischler, 1977; Shelton \& Martin, 1992). Second, with respect to their processing deficit, the data indicate that language comprehension impairments in aphasic patients are due to an impairment in the integration of individual word meanings into an overall meaning representation. This conclusion can be drawn on the basis of several pieces of evidence. The stimulus onset asynchrony (SOA) between primes and targets in this experiment was $1,183 \mathrm{msec}$. It has been shown that the priming effects that are observed at long SOAs are largely due to the use of primes for generating expectancies about possible targets (Becker, 1980, 1985; Posner \& Snyder, 1975) and/or to a postlexical process, which has been referred to as postlexical meaning integration (De Groot, 1985) or semantic matching (Neely \& Keefe, 1989). In addition, the $\mathrm{N} 400$ effect is sensitive to the lexical integration process, and, in the absence of a task, the N400 effect most likely reflects the process of semantic matching (Chwilla, 


\title{
Normal Controls
}

\author{
Broca's Aphasics
}

Wernicke's aphasics
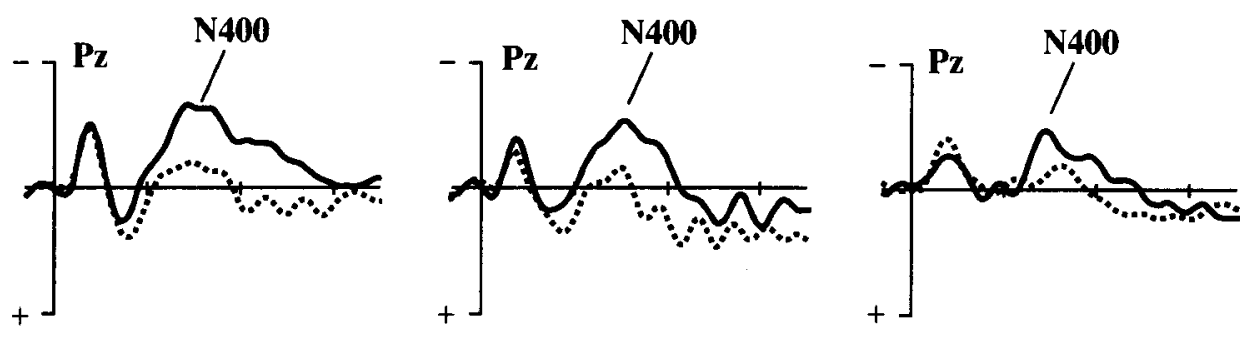

Associative

List
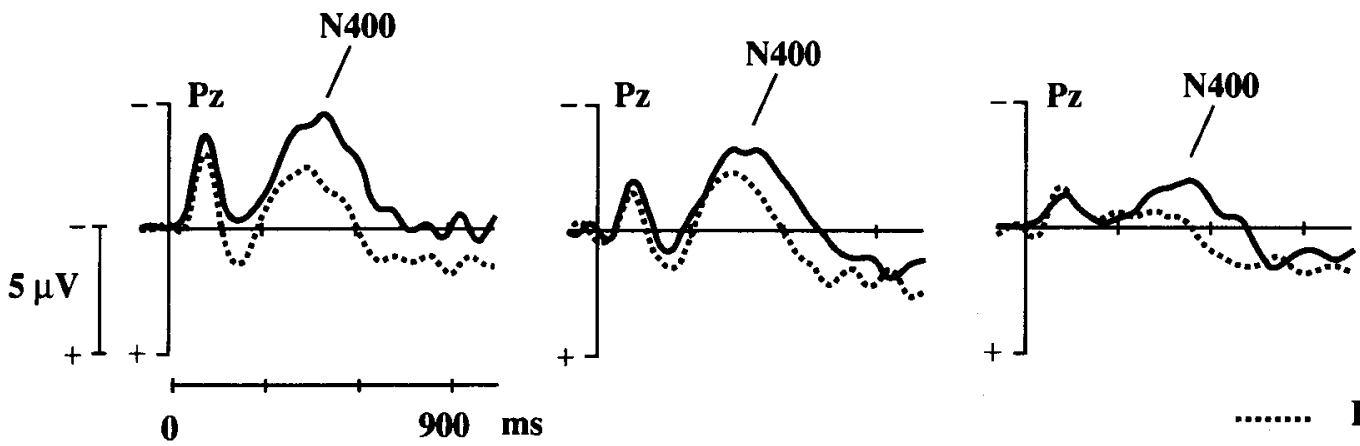

\section{Semantic} List

\section{Related}

Figure 1. Grand average ERPs at the parietal midline electrode (Pz) for normal controls $(N=12)$, Broca's aphasics $(N=13)$, and Wernicke's aphasics $(N=8)$ in the associative and the semantic list for the unrelated targets (solid line), and the related targets (dotted line). Data are from "Lexical-Semantic Event-Related Potential Effects in Patients With Left Hemisphere Lesions and Aphasia, and Patients With Right Hemisphere Lesions Without Aphasia," by P. Hagoort, C. M. Brown, and T. Y. Swaab, 1996, Brain, 119, pp. 627-649. Copyright 1996 by Oxford University Press. Adapted with permission.

1996). Together, the relatively long SOA between primes and targets, the absence of a task, and the evidence about the processing nature of the N400 suggest that the N400 priming effects that were observed in this experiment were generated by a semantic matching process. In this process, subjects match primes and targets for semantic similarity. A successful match leads to a reduction of the N400 amplitude. Therefore, the impairments, in aphasic patients who have moderate to severe comprehension deficits, in the matching of related words for their semantic similarity suggests that the functional locus of language comprehension problems in these patients is at the level of integrating individual word meanings into an overall meaning representation of the whole utterance.

In the second study (Swaab et al., 1997), subjects were asked to listen to sentences that were spoken at a normal rate. In half of the sentences, the meaning of the sentence-final word was anomalous with respect to the preceding sentence context ("The girl dropped the candy on the $s k y$ "); in the other half of the sentences, the sentencefinal word matched the semantic specifications of the preceding sentence context ("The children like to play in the garden"). The N400 was measured to the sentencefinal words in both conditions. In normal subjects, the $\mathrm{N} 400$ to sentence-final congruent words is typically reduced relative to the $\mathrm{N} 400$ to sentence-final anomalous words (Kutas \& Hillyard, 1980). This effect reflects the fact that, in the congruent condition, the sentence-final word was easy to integrate into the preceding sentence context, whereas this was not the case in the anomalous condition. The results for the aphasic patients were analyzed according to the severity of their comprehension deficit. The results showed that, in contrast to the normal controls, the low comprehenders had a smaller and clearly delayed $\mathrm{N} 400$ effect. The high comprehenders showed an N400 effect that was comparable to that of the neurologically unimpaired controls. Also, the N400 effect for the right-hemisphere controls was not significantly different from that for the normal controls (see Figure 2).

One interpretation for this delay in the $\mathrm{N} 400$ effect of the low comprehenders is in terms of a deficit in accessing lexical information. Impaired access to lexical information for different words in the sentence could result in a delayed integration of the sentence-final word and hence in a delay of the N400 congruity effect. However, this interpretation seems unlikely in the light of the results from recent studies that show that aphasic patients with comprehension deficits do not have a deficit in accessing lexical information (see, e.g., Hagoort, 1993, 1997; Tyler et al., 1995). Instead, given the processing nature of the $\mathrm{N} 400$, the results of this study indicate that 

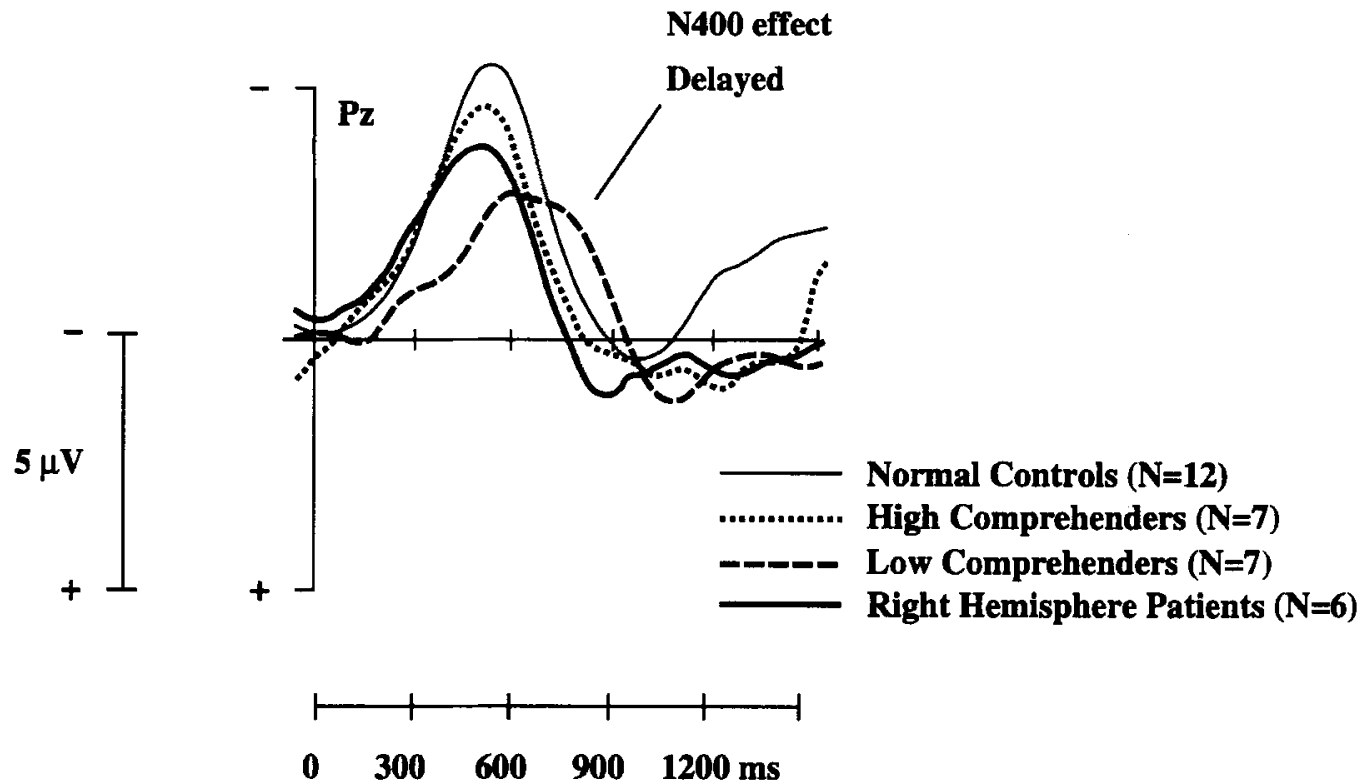

Figure 2. Grand average difference waveforms (anomalous minus congruent) at the parietal midline electrode (Pz) for 12 normal controls (thin solid line), 7 high comprehenders (dotted line), 7 low comprehenders (dashed line), and 6 right-hemisphere patients (thick solid line). Low comprehenders have a smaller, delayed N400 effect. Data are from "Spoken Sentence Comprehension in Aphasia: Event-Related Potential Evidence for a Lexical Integration Deficit," by T. Y. Swaab, C. Brown, and P. Hagoort, 1997, Journal of Cognitive Neuroscience, 9, Figure 6, p. 50. Copyright 1997 by MIT Press. Adapted with permission.

these patients are slower than is normal in the process of integrating lexical information into the overall meaning of the entire utterance.

The third study further investigated possible delays in lexical integration by examining the time course of the resolution of lexically ambiguous words in sentence context (Swaab et al., in press). Ambiguous words have the same form representation but two or more unrelated meanings (e.g., bank). Selection of the contextually appropriate meaning of ambiguous words in sentence context requires the rapid integration of this meaning with the preceding context. In this study, the subjects were presented with sentences in three different context conditions, followed by a target word that was presented either 100 or $1,250 \mathrm{msec}$ after the offset of the sentence-final word. In the concordant condition, the sentence biased the subordinate meaning of the sentence-final ambiguous word that was related to the target ("The tall man planted a tree on the bank/slope"). In the discordant context, the sentence biased the alternative (dominant) meaning of the sentence-final word ("The poor man made a call to the bank/slope"). This meaning was unrelated to the target. And finally, in the unrelated condition, the sentence-final word was neither ambiguous nor related to the target ("The busy man gave his ticket to the boy/ slope"). The N400 was measured to the target words (slope in the example).

Contextual selection of the appropriate meaning of the sentence-final ambiguous word is evident from the fol- lowing pattern of $\mathrm{N} 400$ results: a reduction of the amplitude of the N400 to the targets in the concordant condition relative to the discordant condition and the same amplitude of the $\mathrm{N} 400$ to the targets in the discordant condition relative to the unrelated condition. As can be seen in Figure 3, this pattern was found for the normal controls in both interstimulus interval (ISI) versions of the experiment (the small difference between the discordant and the unrelated condition in the short ISI version of the experiment was not significant). This indicates that there were no relevant changes over time in the selectional status of the subordinate meaning for the normal controls: They had selected the contextually appropriate meaning of ambiguous words within a very short period of time. In contrast to the elderly controls, the Broca's aphasics did show a significant change in their pattern of ERP results over time (see Figure 3 ). The patients showed the same pattern of results as that for the normals at the $1,250 \mathrm{msec}$ ISI. Their N400 effects differed from those of the normal controls at the short ISI. In the short ISI version of the experiment, the Broca's aphasics showed clear activation of the subordinate meaning when it was contextually inappropriate (i.e., a reduction of the N400 amplitude to the targets in the discordant condition relative to the unrelated condition).

Two conclusions can be drawn from this pattern of results. First, in contrast to claims by Swinney et al. (1989), Broca's aphasics are able to access the subordinate meaning of ambiguous words. And second, these data indicate 
ISI $=100$
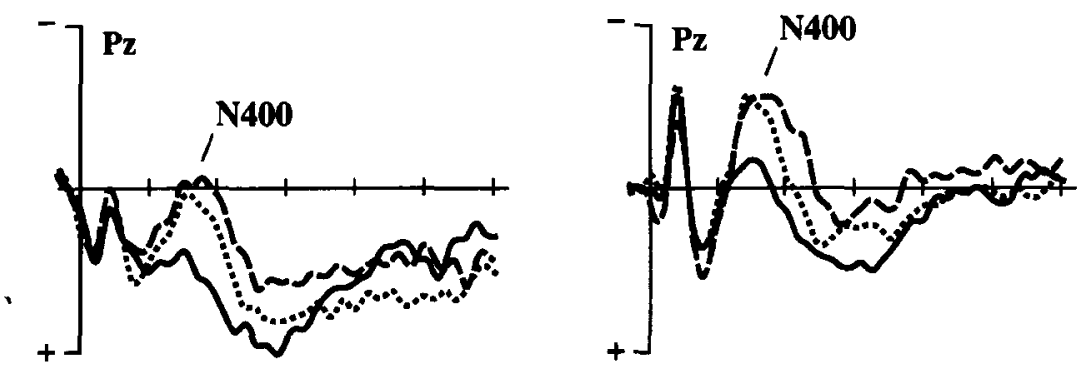

\section{Normal Controls}
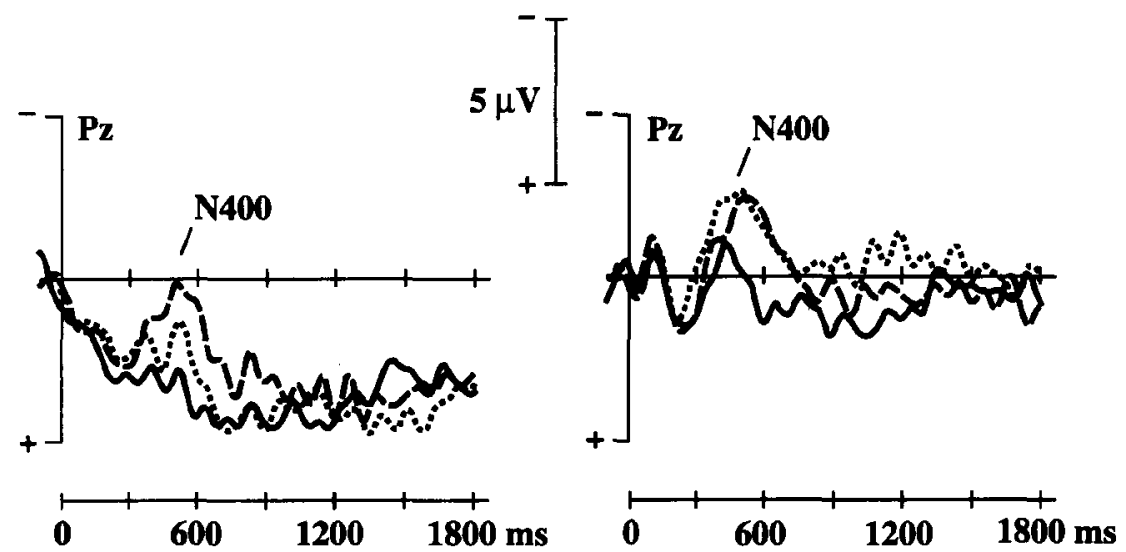

\section{Broca's Aphasics}

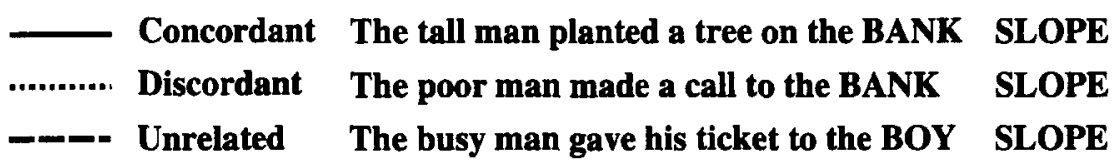

Figure 3. Grand average ERPs from normal controls $(N=12)$ and Broca's aphasics $(N=12)$ at the parietal midline electrode site (Pz) to the targets in the concordant (solid line), discordant (dotted line), and unrelated (dashed line) context conditions, in the short and the long ISI versions of the experiment. Data are from "Understanding Ambiguous Words in Sentence Contexts: Electrophysiological Evidence for Delayed Contextual Selection in Broca's Aphasia," by T. Y. Swaab, C. Brown, and P. Hagoort, 1998, Neuropsychologia, Figures 4-7. Copyright 1998 by Elsevier Science, Ltd. Adapted with permission.

that the contextual selection of the appropriate meaning of ambiguous words is delayed in these patients. Because the contextual selection of ambiguous words depends on the rapid integration of the appropriate meaning into the preceding context, this delay in contextual selection is most likely due to a delay in the time course of lexical integration.

\section{CONCLUDING REMARKS}

The results of the ERP studies in aphasic patients reviewed here have shown that reliable language-related ERP effects can be obtained in brain-damaged patients with a language impairment, even in the absence of overt task requirements. These ERP effects could be interpreted with regard to the functional nature of the aphasic's neurolinguistic deficit, because key methodological con- trols permitted us to have confidence in assigning changes in the aphasics' N400 effects to changes in language processes. Provided that some methodological concerns are kept in mind and controlled, the use of ERPs offers a fruitful approach to the study of questions about the underlying nature of cognitive deficits in brain-damaged patients.

\section{REFERENCES}

Basso, A., Lecours, A. R., Moraschini, S., \& Vanier, M. (1985). Anatomoclinical correlations of the aphasias as defined through computerized tomography: Exceptions. Brain \& Language, 26, 201-229.

Bates, E., Appelbaum, M., \& Allard, L. (1991). Statistical constraints on the use of single cases in neuropsychological research. Brain \& Language, 40, 295-329.

BAUM, S. R. (1989). On-line sensitivity to local and long-distance syntactic dependencies in Broca's aphasia. Brain \& Language, 37, 327-338.

BECKER, C. A. (1980). Semantic context effects in visual word recognition: An analysis of semantic strategies. Memory \& Cognition, 8, 493-512. 
BECKER, C. A. (1985). What do we really know about semantic context effects during reading? In D. Besner, T. G. Waller, \& E. M. MacKinnon (Eds.), Reading research: Advances in theory and practice (pp. 125169). Toronto: Academic Press.

Berndt, R. S., \& CaramazZa, A. (1980). Semantic operations deficits in sentence comprehension. Psychological Research, 41, 169-177.

Besson, M., \& MaCaR, F. (1987). An event-related potential study of incongruity in music and other non-linguistic contexts. Psychophysiology, 24, 14-25.

Blumstein, S. E., Milberg, W., \& Shrier, R. (1982). Semantic processing in aphasia: Evidence from an auditory lexical decision task. Brain \& Language, 17, 301-315.

Brown, C. M., \& HAGOORT, P. (1993). The processing nature of the N400: Evidence from masked priming. Journal of Cognitive Neuroscience, 5, 34-44.

Brunia, C. H. M., Möcks, J., Van Den Berg-Lenssen, M. M. C. (1989). Correcting ocular artifacts in the EEG: A comparison of several methods. Journal of Psychophysiology, 3, 1-50.

BUB, J., \& BUB, D. (1988). On the methodology of single-case studies in cognitive neuropsychology. Cognitive Neuropsychology, 5, 565-582

CaPLan, D. (1988). On the role of group studies in neuropsychological and pathopsychological research. Cognitive Neuropsychology, 5 , 535-547.

Caplan, D., Baker, C., \& Dehaut, F. (1985). Syntactic determinants of sentence comprehension in aphasia. Cognition, 21, 117-175.

CaramazzA, A. (1986). On drawing inferences about the structure of normal cognitive systems from the analysis of patterns of impaired performance: The case for single-patient studies. Brain \& Cognition, 5, 41-66

CaRamazZa, A. (1992). Is cognitive neuropsychology possible? Jour nal of Cognitive Neuroscience, 4, 80-95.

Caramazza, A., \& BaDeCKER, W. (1989). Patient classification in neuropsychological research. Brain \& Cognition, 10, 256-295.

Caramazza, A, \& McCloskey, M. (1988). The case for single-patient studies. Cognitive Neuropsychology, 5, 517-527.

CHWILLA, D. J. (1996). Electrophysiology of word processing: The lexical processing nature of the $N 400$ priming effect. Unpublished doctoral dissertation, Nijmegen University.

Chwilla, D. J., Brown, C. M., \& HaGoort, P. (1995). The N400 as a function of the level of processing. Psychophysiology, 32, 274-285.

Cunnington, R., Iansek, R., Bradshaw, J. L., \& Phillips, J. G. (1995). Movement-related potentials in Parkinson's disease. Presence and predictability of temporal and spatial cues. Brain, 118, 935-950.

DE GROOT, A. M. (1985). Word-context effects in word naming and lexical decision. Quarterly Journal of Experimental Psychology, 37A, 281-297.

Donchin, E. (1979). Event-related brain potentials: A tool in the study of human information processing. In $\mathrm{H}$. Begleiter (Ed.), Evoked brain potentials and behavior (pp. 13-88). New York: Plenum.

Donchin, E. (1981). Surprise ... Surprise? Psychophysiology, 18, 493-513.

Donchin, E., \& Coles, M. G. H. (1988). Is the P300 component a manifestation of context updating? Behavioral \& Brain Sciences, 11 357-374.

DronKers, N. F. (1996). A new region for coordinating speech articulation. Nature, 384, 159-161.

FISCHLER, I. (1977). Semantic facilitation without association in a lexical decision task. Memory \& Cognition, 5, 335-339.

Ford, J. M., Pfefferbaum, A., \& RoTh, W. (1992). P3 and schizophrenia. In D. Friedman \& G. E. Bruder (Eds.), Psychophysiology and experimental psychopathology: A tribute to Samuel Sutton (Annals of the New York Academy of Sciences, Vol. 658, pp. 146-162). New York: New York Academy of Sciences.

FrIEDERICI, A. D. (1983). Aphasics' perception of words in sentential context: Some real time processing evidence. Neuropsychologia, 21, 351-358.

FRIEDERICI, A. D. (1985). Levels of processing and vocabulary types: Evidence from on-line comprehension in normals and agrammatics. Cognition, 19, 133-166
FrIeDERICI, A. D. (1995). The time course of syntactic activation during language processing: A model based on neuropsychological and neurophysiological data. Brain \& Language, 50, 259-281.

FrIederICI, A. D., \& KilBoRN, K. (1989). Temporal constraints on language processing: Syntactic priming in Broca's aphasia. Journal of Cognitive Neuroscience, 1, 262-272.

Friederici, A. D., Pfeifer, E., \& Hahne, A. (1993). Event-related brain potentials during natural speech processing: Effects of semantic, morphological and syntactic violations. Cognitive Brain Research, 1, 183-192.

Friederici, A. D., Wessels, J. M., Emmorey, K., \& Bellugi, U. (1992). Sensitivity to inflectional morphology in aphasia: A real time processing perspective. Brain \& Language, 43, 747-763.

Friedman, D., Simpson, G., \& Hamberger, M. (1993). Age-related changes in scalp topography to novel and target stimuli. Psychophysiology, 30, 383-396.

Galambos, R., Hicks, G., \& Wilson, M. J. (1982). Hearing loss in graduates of a tertiary intensive care nursery. Ear Hear, 3, 87-90.

GoODGLASS, H., \& BAKER, E. (1976). Semantic field, naming, and auditory comprehension in aphasia. Brain \& Language, 3, 359-374.

Graetz, P., De Bleser, R., \& Willmes, K. (1992). De Akense afasie test. Lisse: Swets \& Zeitlinger.

GraF, P., \& MANDLER, G. (1984). Activation makes words more accessible, but not necessarily more retrievable. Journal of Verbal Learning \& Verbal Behavior, 23, 553-568.

GratTON, G. (1998). Dealing with artifacts: The EOG contamination of the event-related brain potential. Behavior Research Methods, Instruments, \& Computers, 30, 44-53.

Gratton, G., Coles, M. G. H., \& Donchin, E. (1983). A new method for off-line removal of ocular artifact. Electroencephalography \& Clinical Neurophysiology, 55, 468-484.

Grober, E., Perecman, E., Kellar, L., \& Brown, J. (1980). Lexical knowledge in anterior and posterior aphasics. Brain \& Language, 10, 318-330.

GunTER, T. C., JACKSON, J. L., \& MULDER, G. (1992). An electrophysiological study of semantic processing in young and middle-aged academics. Psychophysiology, 29, 38-54.

HaARManN, H. J., \& KolK, H. H. J. (1991). Syntactic priming in Broca's aphasics: Evidence for slow activation. Aphasiology, 5, 247-263.

HaARMANN, H. J., \& KolK, H. H. J. (1994). On-line sensitivity to subjectverb agreement violations in Broca's aphasics: The role of syntactic complexity and time. Brain \& Language, 46, 493-516.

HAGOORT, P. (1990). Tracking the time course of language understanding in aphasia. Zutphen: Koninklijke Wöhrmann.

HAGOORT, P. (1993). Impairments of lexical-semantic processing in aphasia: Evidence from the processing of lexical ambiguities. Brain \& Language, 45, 189-232.

HAGOORT, P. (1997). Semantic priming in Broca's aphasics at a shor SOA: No support for an automatic access deficit. Brain \& Language, 56, 287-300.

HaGoOrt, P., Brown, C., \& Groothusen, J. (1993). The syntactic positive shift (SPS) as an ERP measure of syntactic processing. Language \& Cognitive Processes, 8, 439-483.

HAGOORT, P., Brown, C. M., \& SWAAB, T. Y. (1996). Lexical-semantic event-related potential effects in patients with left hemisphere lesions and aphasia, and patients with right hemisphere lesions without aphasia. Brain, 119, 627-649.

HAGOORT, P., \& KUTAS, M. (1995). Electrophysiological insights into language deficits. In F. Boller \& J. Grafman (Eds.), Handbook of neuropsychology (Vol. 10, pp. 105-134). Amsterdam: Elsevier.

HALLIDAY, A. M. (ED.) (1982). Evoked potentials in clinical testing (Clinical Neurology and Neurosurgery Monographs, Vol. 3). Edinburgh: Churchill Livingstone.

Heinze, H.-J., Mangun, G. R., Burchert, W., Hinrichs, H., Scholz, M., Münte, T. F., Gös, A., Scherg, M., Johannes, S., Hundeshagen, H., Gazzaniga, M. S., \& Hillyard, S. A. (1994). Combined spatial and temporal imaging of brain activity during visual selective attention in humans. Nature, 372, 543-546.

Heinze, H.-J., Münte, T. F., Gobiet, W., Niemann, H., \& Ruff, R. M. 
(1992). Parallel and serial visual search after closed head injury: Electrophysiological evidence for perceptual dysfunctions. Neuropsychologia, 30, 495-514.

HoLcomB, P. J. (1993). Semantic priming and stimulus degradation: Implications for the role of the $\mathrm{N} 400$ in language processing. Psychophysiology, 30, 47-61.

Holcomb, P. J., \& Neville, H. J. (1991). Natural speech processing: An analysis using event-related brain potentials. Psychobiology, 19, 286-300.

Iragui, V. J., Kutas, M., Mitchener, M. R., \& Hillyard, S. A. (1993). Effects of aging on event-related brain potentials and reaction times in an auditory oddball task. Psychophysiology, 30, 10-22.

Johannes, S., Mangun, G. R., Kussmaul, C. L., \& Münte, T. F. (1995). Brain potentials in developmental dyslexia: Differential effects of word frequency in human subjects. Neuroscience Letters, 195, 183-186.

JOHNSON, R, JR. (1988). The amplitude of the P300 component of the event-related potential: Review and synthesis. In P. K. Ackles, J. R. Jennings, \& M. G. H. Coles (Eds.), Advances in psychophysiology (Vol. 3, pp. 69-137). Greenwich, CT: JAI.

JONES, S. (1982). Clinical applications of short-latency somatosensory evoked potentials. In I. Bodis-Wollner (Ed.), Evoked potentials (Annals of the New York Academy of Sciences, Vol. 388, pp. 369-387). New York: New York Academy of Sciences.

Karayanidis, F, Andrews, S., Ward, P. B., \& Michie, P. T. (1995). ERP indices of auditory selective attention in aging and Parkinson's disease. Psychophysiology, 32, 335-350.

KING, J. W., \& KUTAS, M. (1995a). Do the waves begin to waver? ERP studies of language processing in the elderly. In P. A. Allen and T. R. Bashore (Eds.), Age differences in word and language processing (Advances in Psychology, Vol. 110, pp. 314-344). Amsterdam: Elsevier.

KING, J. W., \& KuTAS, M. (1995b). Who did what to whom and when? Using word- and clause-level ERPs to monitor working memory usage in reading. Journal of Cognitive Neuroscience, 7, 376-395.

Kluender, R., \& Kutas, M. (1993). Bridging the gap: Evidence from ERPs on the processing of unbounded dependencies. Journal of Cognitive Neuroscience, 5, 196-214.

KNIGHT, R. T. (1987). Aging decreases auditory event-related potentials to unexpected stimuli in humans. Neurobiology of Aging, 8, 109-113.

KNIGHT, R. T. (1996). Contribution of human hippocampal region to novelty detection. Nature, 383, 256-259.

KNIGHT, R. T. (1997). Electrophysiological methods in behavioral neurology and neurophysiology. In T. E. Feinberg and M. Farah (Eds.), Behavioral neurology and neuropsychology (pp. 101-120). New York: McGraw-Hill,

Kraus, N., MCGee, T. J., Carrell, T. D., Zecker, S. G., Nicol, T. G., \& КосH, D. B. (1996). Auditory neurophysiologic responses and discrimination deficits in children with learning problems. Science, $\mathbf{2 7 3}$ 971-973.

Kuroiwa, Y., \& CELESIA, G. (1981). Visual evoked potentials with hemifield pattern stimulation: Their use in the diagnosis of retrochiasmatic lesions. Archives of Neurology, 38, 86-90.

Kutas, M., \& Hillyard, S. A. (1980). Reading senseless sentences: Brain potentials reflect semantic incongruity. Science, 207, 203-205.

KuTAS, M., \& Hillyard, S. A. (1983). Event-related brain potentials to grammatical errors and semantic anomalies. Memory \& Cognition, 11, 539-550.

Kutas, M., Hillyard, S. A., \& Gazzaniga, M. S. (1988). Processing of semantic anomaly by right and left hemispheres of commissurotomy patients: Evidence from event-related brain potentials. Brain, 111, 553-576.

Kutas, M., Neville, H. J., \& Holcomb, P. J. (1987). A preliminary comparison of the $\mathrm{N} 400$ response to semantic anomalies during reading, listening, and signing. Electroencephalography \& Clinical Neurophysiology, 39(Suppl.), 325-330.

Mangun, G. R., Hopfinger, J. B., \& Heinze, H.-J. (1998). Integrating electrophysiology and neuroimaging in the study of human cognition. Behavior Research Methods, Instruments, \& Computers, 30 , 118-130.

MCCARTHY, G., \& Wood, C. C. (1985). Scalp distributions of eventrelated potentials: An ambiguity associated with analysis of variance models. Electroencephalography \& Clinical Neurophysiology, 62, 203-208.

McCloskey, M., \& Caramazza, A. (1988). Theory and methodology in cognitive neuropsychology: A response to our critics. Cognitive Neuropsychology, 5, 583-623.

MilberG, W., \& Blumstein, S. E. (1981). Lexical decision and aphasia: Evidence for semantic processing. Brain \& Language, 14, 371-385.

Milberg, W., Blumstein, S. E., \& Dworetzky, B. (1987). Processing of lexical ambiguities in aphasia. Brain \& Language, 31, 138-150.

Milberg, W., Blumstein, S., Katz, D., Gershberg, F., \& Brown, T. (1995). Semantic facilitation in aphasia: Effects of time and expectancy. Journal of Cognitive Neuroscience, 7, 33-50.

MüntE, T. F., HeinzE, H.-J., \& MANGUN, G. R. (1993). Dissociation of brain activity related to semantic and syntactic aspects of language. Journal of Cognitive Neuroscience, 5, 335-344.

NEELY, J. H. (1991). Semantic priming effects in visual word recognition: A selective review of current findings and theories. In D. Besner \& G. Humphreys (Eds.), Basic processes in reading: Visual word recognition (pp. 264-336). Hillsdale, NJ: Erlbaum.

NeeLY, J. H., \& KeEFE, D. E. (1989). Semantic context effects on visual word processing: A hybrid prospective/retrospective processing theory. In G. H. Bower (Ed.), The psychology of learning and motivation: Advances in research and theory (Vol. 24, pp. 207-248). New York: Academic Press.

Neville, H. J., Nicol, J. L., Barss, A., Forster, K. I., \& Garret, M. (1991). Syntactically based sentence processing classes: Evidence from event-related potentials. Journal of Cognitive Neuroscience, 3, 151-165.

Ober, B. A., \& Shenaut, G. K. (1995). Theoretical and practical issues in semantic priming research with Alzheimer's disease subjects. In L. Dilalla \& S. M. Clancy-Dollinger (Eds.), Assessment of biological mechanisms across the lifespan (pp. 121-150). Hillsdale, NJ: Erlbaum.

OSterhout, L., \& HolcomB, P. J. (1992). Event-related brain potentials elicited by syntactic anomaly. Journal of Memory \& Language, 31, 785-806.

OSTRIN, R. K., \& TYLER, L. K. (1993). Automatic access to lexical semantics in aphasia: Evidence from semantic and associative priming. Brain \& Language, 45, 147-159.

Pfefferbaum, A., Ford, J. M., White, P. M., \& Roth, W. T. (1989). P3 in schizophrenia is affected by stimulus modality, response requirements, medication status, and negative symptoms. Archives of General Psychiatry, 46, 1035-1044.

Poeck, K., De Bleser, R., \& von Keyserlingk, D. G. (1984). Computed tomography localization of standard aphasia syndromes. In F. C. Rose (Ed.), Advances in neurology 42: Progress in aphasiology (pp. 71-89). New York: Raven.

PoLICH, J. (1996). Meta-analysis of P300 normative aging studies. Psychophysiology, 33, 334-353.

PoliCH, J., \& KoK, A. (1995). Cognitive and biological determinants of P300: An integrative review. Biological Psychology, 41, 103-146.

Polich, J., Ladish, C., \& BloOM, F. E. (1990). P300 assessment of early Alzheimer's disease. Electroencephalography \& Clinical Neurophysiology, 77, 179-189.

Posner, M. I., \& SNyder, C. R. R. (1975). Attention and cognitive control. In R. L. Solso (Ed.), Information processing and cognition: The Loyola symposium (pp. 55-85). Hillsdale, NJ: Erlbaum.

Praamstra, P., Meyer, A. S., Cools, A. R., Horstink, M. W., \& Stegeman, D. F. (1996). Movement preparation in Parkinson's disease: Time course and distribution of movement related potentials in a movement precueing task. Brain, 119, 1689-1704.

Pritchard, W. S. (1986). Cognitive event-related potential correlates of schizophrenia. Psychological Bulletin, 100, 43-66.

Proverbio, A. M., Zani, A., Gazzaniga, M. S., \& Mangun, G. R. M. (1994). ERP and RT signs of a rightward bias for spatial orienting in a split brain patient. NeuroReport, 5, 2457-2461.

REGAN, D. (1989). Human brain electrophysiology: Evoked potentials and evoked magnetic fields, in science and medicine. New York: Elsevier.

Renault, B., Signoret, J.-L., Debruille, B., Breton, F., \& BolGERT, F. (1989). Brain potentials reveal covert face recognition in prosopagnosia. Neuropsychologia, 27, 905-912.

Robertson, L. C., Knight, R. T., Rafal, R., \& Shimamura, A. P. 
(1993). Cognitive neuropsychology is more than single-case studies. Journal of Experimental Psychology: Learning, Memory, \& Cognition, 19, 710-717.

RUGG, M. D., FURDA, J., \& LoRIST, M. (1988). The effects of task on the modulation of event-related potentials by word repetition. Psychophysiology, 25, 55-63.

RugG, M. D., Pearl, S., Walker, P., Roberts, R. C., \& Holdstock, J. S. (1994). Word repetition effects on event-related potentials in healthy young and old subjects, and in patients with Alzheimer-type dementia. Neuropsychologia, 32, 381-398.

Rugg, M. D., Roberts, R. C., Potter, D. D., Pickles, C. D., \& Nagy, M. E. (1991). Event-related potentials related to recognition memory. Effects of unilateral temporal lobectomy and temporal lobe epilepsy. Brain, 114, 2313-2332.

Schwartz, T. J., Kutas, M., Butters, N., Paulsen, J. S., \& Salmon, D. P. (1996). Electrophysiological insights into the nature of the semantic deficit in Alzheimer's disease. Neuropsychologia, 34, 827-841.

ShELTON, J. R., \& MARTIN, R. C. (1992). How semantic is automatic semantic priming? Journal of Experimental Psychology: Learning, Memory, \& Cognition, 18, 1191-1210.

Smith, A., \& Picton, T. (1985). Neonatal hearing assessment by auditory brainstem response - the Canadian experience. Journal of Otolaryngology, 14(Suppl.), 1-55.

Stockard, J. J., Stockard, J. E., \& Sharbrough, F. (1980). Brainstem auditory evoked potentials in neurology: Methodological interpretation, clinical applications. In M. J. Amninoff (Ed.), Electrodiagnosis in clinical neurology (pp. 370-413). New York: Churchill Livingstone.

SWAAB, T. Y., Brown, C., \& HAGOORT, P. (1997). Spoken sentence comprehension in aphasia: Event-related potential evidence for a lexical integration deficit. Journal of Cognitive Neuroscience, 9, 39-66.

SWAab, T. Y. Brown, C., \& Hagoort, P. (in press). Understanding ambiguous words in sentence contexts: Electrophysiological evidence for delayed contextual selection in Broca's aphasia. Neuropsychologia.

Swick, D., Kutas, M., \& Neville, H. J. (1994). Localizing the neural generators of event-related brain potentials. In. A. Kertesz (Ed.), Localization and neuroimaging in neuropsychology. Foundations of neuropsychology (pp. 73-121). San Diego: Academic Press.

SWINNEY, D. A., ZURIF, E., \& Nicol, J. (1989). The effects of focal brain damage on sentence processing: An examination of the neurological organization of a mental module. Journal of Cognitive Neuroscience, 1, 25-37.

TYLER, L. K. (1985). Real time comprehension processes in agrammatism: A case study. Brain \& Language, 26, 259-275.

TYLER, L. K., \& OSTRIN, R. K. (1994).The processing of simple and complex words in an agrammatic patient: Evidence from priming Neuropsychologia, 32, 1001-1013.

Tyler, L. K., Ostrin, R. K., Cooke, M., \& Moss, H. E. (1995). Automatic access of lexical information in Broca's aphasics: Against the automaticity hypothesis. Brain \& Language, 48, 131-162.

Van Petten, C., \& Kutas, M. (1991). Influences of semantic and syntactic context on open- and closed-class words. Memory \& Cognition, 19, 95-112.

VERLEGER, R. (1991). The instruction to refrain from blinking affects auditory P3 and N1 amplitudes. Electroencephalography \& Clinical Neurophysiology, 78, 240-251

Whitaker, H. A., \& SlotNick, H. B. (1988). Comments on "The case for single patient studies": Is (neuro)psychology possible? Cognitive Neuropsychology, 5, 529-534.

Yamaguchi, S., \& Knight, R. T. (1991). Anterior and posterior association cortex contributions to the somatosensory P300. Journal of Neuroscience, 11, 2039-2054.

Zurif, E. B., Caramazza, A., Myerson, R., \& Galvin, J. (1974). Semantic feature representations for normal and aphasic language Brain \& Language, 1, 167-187.

ZURIF, E. [B.], SWINNEY, D., \& FodOR, J. (1991). An evaluation of assumptions underlying the single-patient-only position in neuropsychological research: A reply. Brain \& Cognition, 16, 198-210.

\section{NOTES}

1. Research, however, that uses the $\mathrm{P} 300$ in schizophrenic patients has not only focused on clinical classification but has been fruitfully applied to the investigation of the nature of the cognitive impairments in this disease. For a cogent discussion of this approach, the reader is referred to Ford et al. (1992).

2 . In addition, it is not desirable to make the experiment very long because, for a variety of reasons, it is often not possible to test brain-damaged patients for more than $2 \mathrm{~h}$. This is one of the practical issues involved in testing patients that will be addressed in more detail later in the text.

3. After brain damage, the assessment of right-handedness may be confounded by the effects of the lesion on the motor system - hence the emphasis on premorbid handedness.

4. Many other variables may be important in the between-group patient versus control comparison, but these are not necessarily specific to the ERP methodology. For a review on specific variables that influence the generation of the P300, see Polich and Kok (1995).

5 . The studies that are reviewed were performed with Colin Brown and Peter Hagoort at the Max Planck Institute for Psycholinguistics, Nijmegen, The Netherlands. 